\title{
Gross Excretion Rates of Natural Marine Phytoplankton and Heterotrophic Uptake of Excreted Products in the Southern North Sea, as Determined by Short-Term Kinetics
}

\author{
C. Lancelot \\ Laboratoire d'Océanographie, Université Libre de Bruxelles, Avenue F.-D. Roosevelt 50, B-1050 Brussels, Belgium
}

\begin{abstract}
Phytoplankton extracellular production has been determined kinetically during the spring phytoplankton bloom in three marine biotopes representative of the Southern North Sea (Scheldt estuary, Belgian coast and English Channel), differing greatly in their biological activities. Short-term kinetics of phytoplankton extracellular compounds produced during ${ }^{14} \mathrm{C}$ incubations have been shown to increase our present capability for estimating gross phytoplankton extracellular production, if compared with a single measure after 4 -h incubation. Underestimates of up to $60 \%$ were found when a fixed incubation of 4 h was used. This underestimate can be attributed either to heterotrophic uptake of excreted products or to the presence of a lagphase in ${ }^{14} \mathrm{C}$ extracellular compounds production, related to physiological propertses of phytoplankton. The data indicate that the phytoplankton extracellular release percentage, expressed with respect to the total photo-assimilated carbon, ranges from 0 to $62 \%$ with lower values in the estuarine area. Seasonal variations show, in Belgian waters and in the English Channel, an increase in phytoplankton excretion percentage during the bloom from about 20 to $60 \%$. Heterotrophic uptake of phytoplankton extracellular products has been calculated from the evolution curve of ${ }^{14} \mathrm{C}$ phytoplankton excretion products by means of a simple mathematical model. Results indicate that heterotrophs can occasionally remove up to $39 \%$ of the total amount of excreted matter per hour indicating that phytoplankton excretion can sometimes produce substances with high turnover
\end{abstract}

\section{INTRODUCTION}

Absorbing energy from the sun, marine phytoplankters fix carbon dioxide by photosynthesis thus initiating the classical food chain: phytoplankton $\rightarrow$ zooplankton $\rightarrow$ fish. A considerable portion of the carbon fixed may be lost from the cells as excreted or released organic matter and thereby contribute to the increase of the dissolved organic carbon pool. This pool supports the growth of planktonic microorganisms, mainly bacteria, which in some coastal areas constitute an important pathway in the carbon cycle (Joiris, 1977).

Accurate estimates of the relative amounts of photoassimilated carbon lost from phytoplankters under various environmental conditions are very important, first for determining the total primary productivity of a given marine ecosystem and, second for better understanding of the carbon cycle.

The classical radiocarbon method for measuring primary production (Steeman Nielsen, 1952) is commonly used as indirect estimate of phytoplankton excretion.
In this method, the radioactivity of the organic carbon contained in a sampled filtrate after a fixed incubation time is regarded as phytoplankton excretion. Studies of natural marine phytoplankton excretion measured by this method are numerous (Hellebust, 1965; Anderson and Zeutschel, 1970; Samuel et al., 1971; Thomas, 1971; Choi, 1972; Berman and Holm-Hansen, 1974; Williams and Yentsch, 1976; Smith et al., 1977). However, there is little agreement on the relative amount, which varies between $0 \%$ and $70 \%$, presumably due to technical difference related to the elimination of the superfluous inorganic ${ }^{14} \mathrm{C}$ method or incubation time. The incubation times adopted vary between 1 and $24 \mathrm{~h}$ and do not seem to have been chosen carefully. Yet incubation time is very important for estimating gross phytoplankton excretion rates because of the presence of heterotrophic microorganisms. Heterotrophs can effectively modify the composition of phytoplankton extracellular compounds through rapid and selective utilization of some of the organic molecules produced during the incubation (Smith, 1974; Nalewajko et al., 


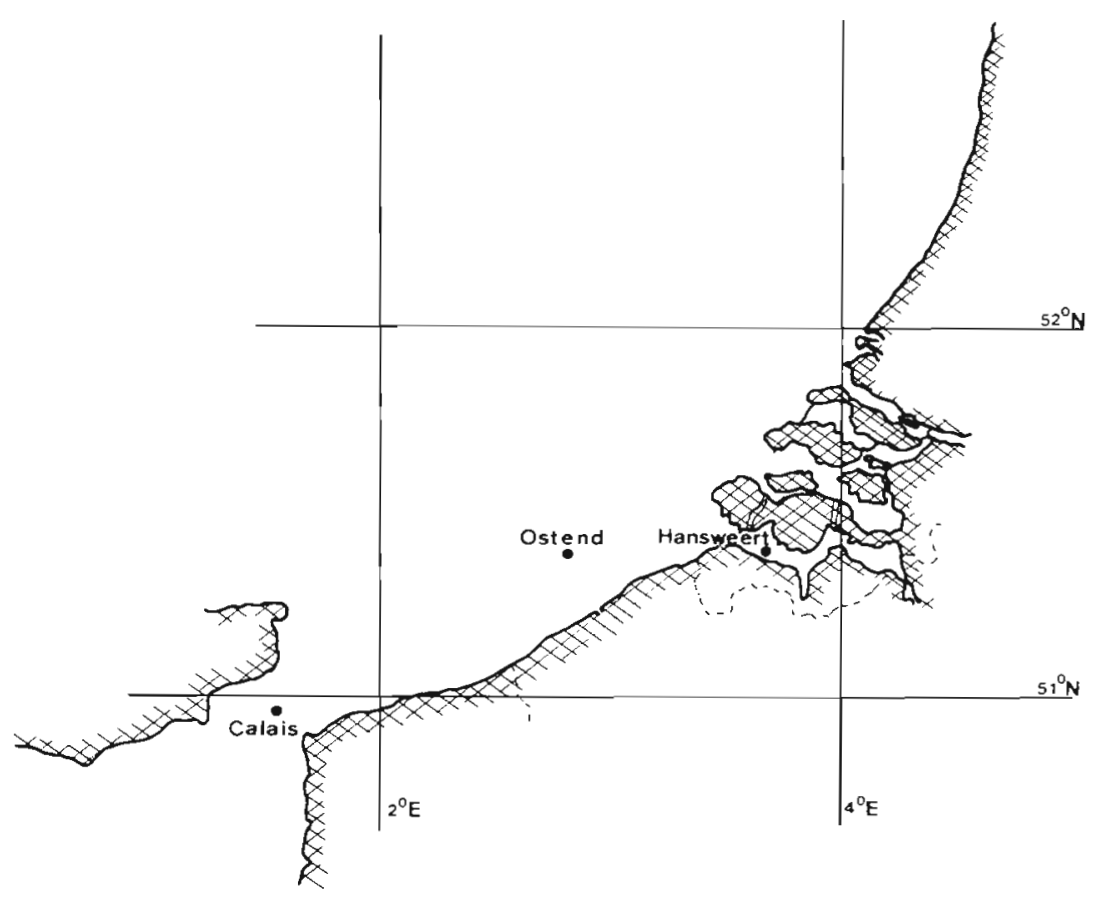

Fig. 1. Locations of the three stations studied

1976). Under these circumstances it is likely that some of the measured rates of extracellular release mentioned above are apparent or net values. The mean error incurred should be difficult to estimate because all different biotopes support different heterotrophic activities.

The present work proposes the use of short-term kinetics of phytoplankton extracellular release as a better basis for estimating gross marine phytoplankton excretion. In order to avoid artefacts produced by variations in illumination, kinetics were first performed under constant illumination (12 000 Lux). Hence the initial slope of the kinetic curve gives the gross phytoplankton excretion rate; any decrease in this slope must be attributed to heterotrophic utilization. From the kinetics; a simple mathematical model has been developed for calculating the relative heterotrophic uptake of phytoplankton extracellular products. For this study, we have chosen three marine biotopes, representative of the Southern North Sea and differing greatly in their heterotrophic activities: an estuarine, a coastal and an open-sea area. The three stations were visited three times during the spring phytoplankton bloom. In addition, two Atlantic stations were sampled during the German expedition Bremerhaven - Panama in May $1978^{\circ}$.

\footnotetext{
- 'Sonne Cruise' organized by Geologisch-Paläontologisches Institut, Univ. Hamburg (Professor Degens) and supported by the Deutsche Forschungsgemeinschaft.
}

\section{MATERIAL AND METHODS}

Figure 1 shows the three stations established for this study. The estuarine station 'Hansweert' is located on the Scheldt estuary, $35 \mathrm{~km}$ from the mouth. Depending on tides, the salinity varies between 19 and $27 \%$. The station 'Ostend' $\left(51^{\circ} 24^{\prime} 00^{\prime \prime} \mathrm{N}, 2^{\circ} 48^{\prime} 00^{\prime \prime} \mathrm{E}\right)$ is located on the Belgian coastal zone of the North Sea, and is influenced by terrestrial inputs. In this zone, the salinity ranges from 30 to $33 \%$ and the mean depth is $15 \mathrm{~m}$. The station 'Calais' $\left(50^{\circ} 57^{\prime} 30^{\prime \prime} \mathrm{N}, 1^{\circ} 23^{\prime} 30^{\prime \prime} \mathrm{E}\right)$, located in the eastern part of the English Channel, is characterized by Atlantic waters with salinities higher than $35 \%$. The coordinates of the two Atlantic stations were $46^{\circ} \mathrm{N}, 15^{\circ} 21^{\prime} \mathrm{W}$ and $41^{\circ} 29^{\prime} \mathrm{N}, 24^{\circ} 58^{\prime} \mathrm{W}$.

Samples were collected at a depth of $3 \mathrm{~m}$ with polyethylene Nyskin's bottles. Seawater was prefiltered immediately on a zooplankton net in order to avoid excessive zooplankton grazing during incubation. One liter of prefiltered seawater was pre-incubated for 30 min in the light incubator (fluorescent lamps, Phillips TL 55) in order to adapt the phytoplankton cells to prevailing light conditions and to avoid artefacts due to light shock. Hundred to two hundred $\mu \mathrm{Ci}$ of $\mathrm{UV}$ irradiated $\mathrm{NaH}^{14} \mathrm{CO}_{3}$ were rapidly added to the sample. After shaking, radioactive seawater was rapidly distributed into 10 pyrex bottles (125 $\mathrm{ml}$ each), one of which was immediately filtered for zero time measurement. The other 9 bottles were then quickly placed into the incubator at in situ temperature. At 4-h intervals, the bottles were filtered on a $0.2-\mu \mathrm{m}$ mem- 
brane filter, using a gentle vacuum $(<100 \mathrm{~mm} \mathrm{Hg})$. Filtrates were collected, acidified with $85 \% \mathrm{H}_{3} \mathrm{PO}_{4}$ to $\mathrm{pH} \mathrm{2-3}$ and then immediately frozen. The superfluous inorganic radioactive carbon was eliminated by lyophilisation following the method of Kelton et al. (1977). After freeze-drying, the material was resuspended in distilled water. The radioactivity contained in the treated filtrate on the one hand, and retained on the filter on the other, was counted by liquid scintillation.

For all sampled stations, chlorophyll pigments were measured using the method of Lorenzen (1967).

\section{RESULTS}

Figure 2 gives the variations of chlorophyll $\alpha$ with time, in the North Sea and in the English Channel. The figure shows that a first phytoplankton bloom occurs in

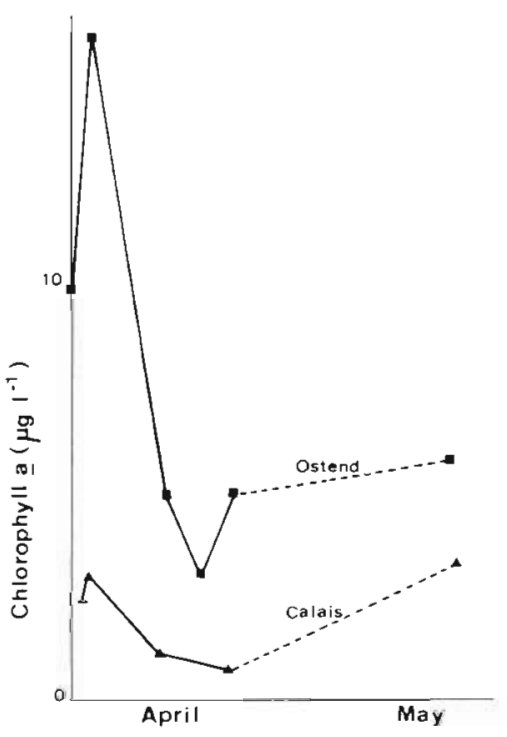

Fig. 2. Spring variations of chlorophyll a

early April. Although there are only a few measurements, the seasonal evolution of the phytoplankton seems to be the same for the two biotopes investigated.

\section{Kinetics}

Three different kinetic curves were obtained depending on the biotope studied and on sampling time: a 'lag-phase' kinetic curve, a 'linear' curve and a 'nonlinear' curve.

\section{'Lag-phase' kinetic curve}

Extracellular products increase linearly with time but after a lag phase (Fig. 3). A small convexity is observed simultaneously for the particulate production

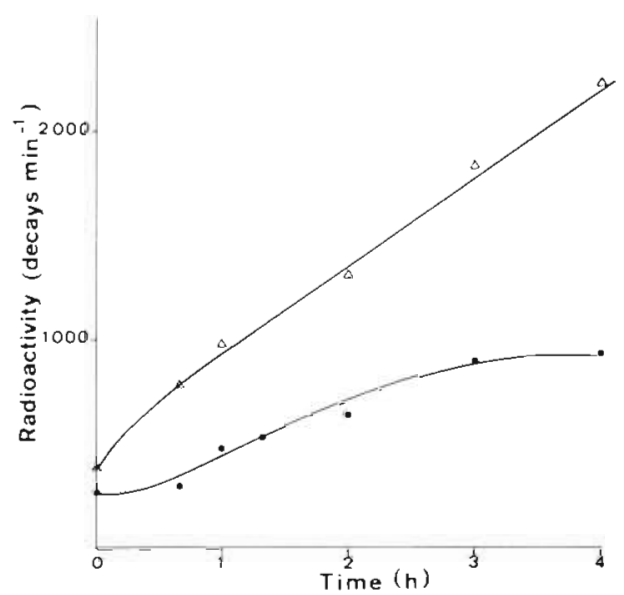

Fig. 3. Four-hour kinetics of phytoplankton particulate production $(\Delta)$ and extracellular release $(\bullet)$ at the Atlantic Station $46^{\circ} \mathrm{N}, 15^{\circ} 21^{\prime} \mathrm{W}$

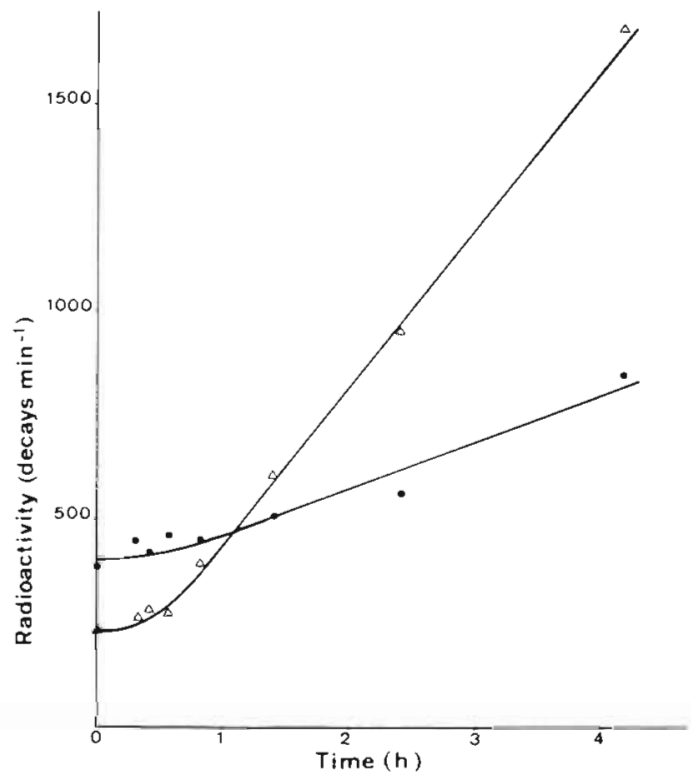

Fig. 4. Four-hour kinetics of phytoplankton particulate production $(\Delta)$ and extracellular release $(\bullet)$ at Calais (180478)

kinetic curve. Such a lag phase in the extracellular release is to be expected when the specific radioactivity of the intracellular pool of organic metabolites that can be exchanged with the external medium does not immediately reach a stable value. Similar observations were made by Thomas (1971) in Atlantic waters.

Such interpretation seems correct because the slope of the tangent to the particulate production curve equals the sum of the rate of particulate production plus the rate of excretion. It must be added that, at very low productivity, a shorter lag phase is also observed in the particulate production (Fig. 4). In this case, no convexity could be observed in the particulate production kinetic curve because the time span between the two lag phases is too short. 
'Linear' kinetic curve

Extracellular products increase linearly with time with the initiation of the experiment (Fig. 5). In this case, as in the preceding one no heterotrophic uptake can be measured during the first $4 \mathrm{~h}$.

\section{'Non-linear' kinetic curve}

A decrease in extracellular rate is observed after rapid linear increase (Fig, 6) or after linear increase following a lag phase (Fig. 3). Under our experimental conditions, this decrease can be attributed to heterotro-

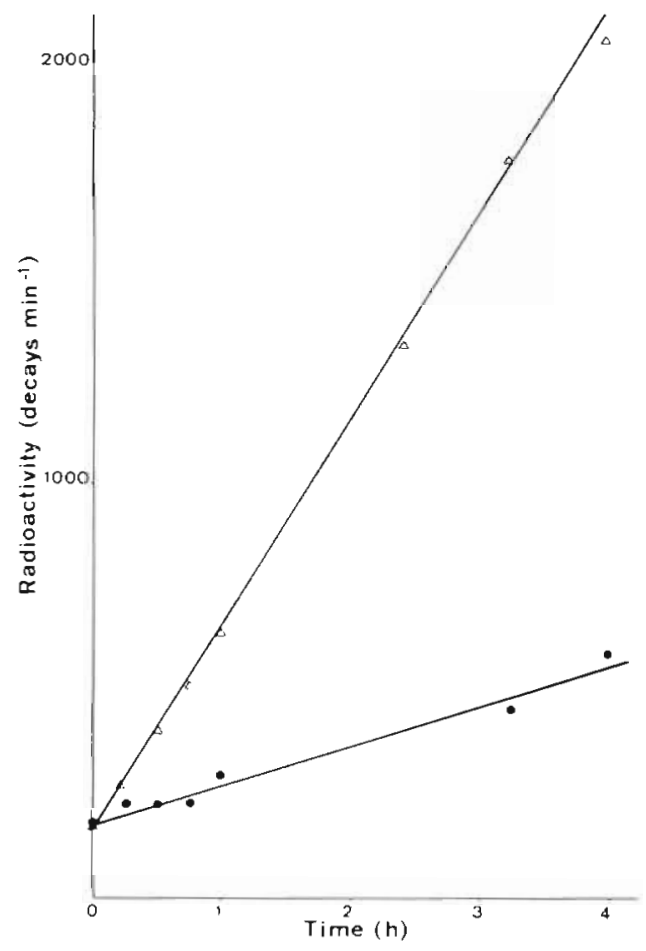

Fig. 5. Four-hour kinetics of phytoplankton particulate production $(\Lambda)$ and extracellular release $(\bullet)$ at Calais (040478)

phic microorganism uptake of phytoplankton extracellular products. For the three biotopes studied, a similar lag phase of about $40 \mathrm{~min}$ is observed in the utilization of algal extracellular products. Uptake intensity, given by the initial slope change, is still very different. In some cases, a decrease in the particulate phytoplankton production, parallel to the decrease in extracellular production, is observed at the end of the experiment (Fig. 7). This must be attributed to phytoplankton respiration or to phytoplankton mortality in the test bottle. When the percentage of extracellular release is not modified, phytoplankton production decrease is probably due to micro-zooplankton grazing.

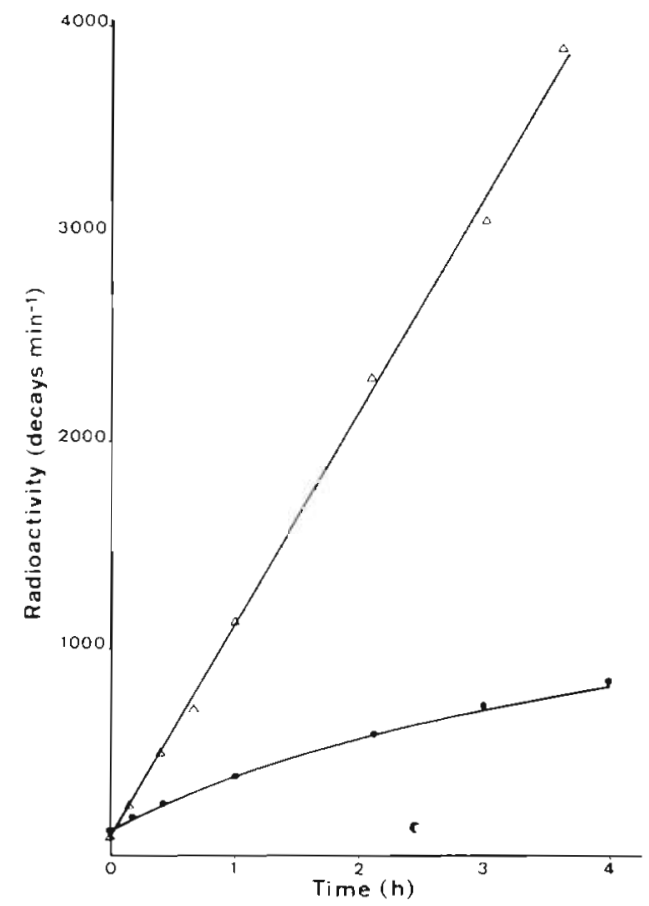

Fig. 6. Four-hour kinetics of phytoplankton particulate production $(\Delta)$ and extracellular release $(\bullet)$ at Ostend (050478)

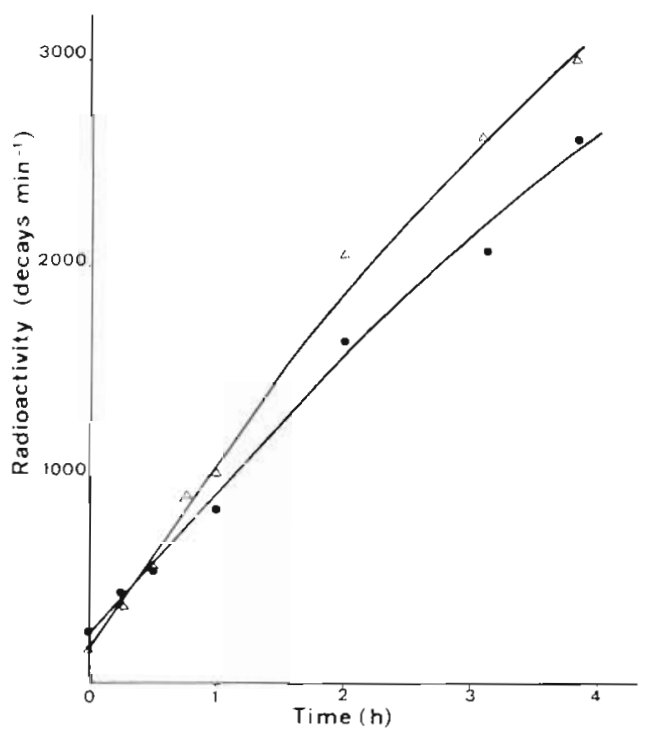

Fig. 7 Four-hour kinetıcs of phytoplankton pariculate production $(A)$ and extracellular release $(\bullet)$ at Ostend (190478)

\section{Variations in Extracellular Release Percentage}

Phytoplankton particulate and extracellular initial rates were calculated from each kinetic curve (slope of the curve in its linear part). For each kinetic, the confidence interval was calculated for a level of $90 \%$. The extracellular release percentage was expressed with respect to the total photo-assimilated carbon. The results are summarized in Table 1. 


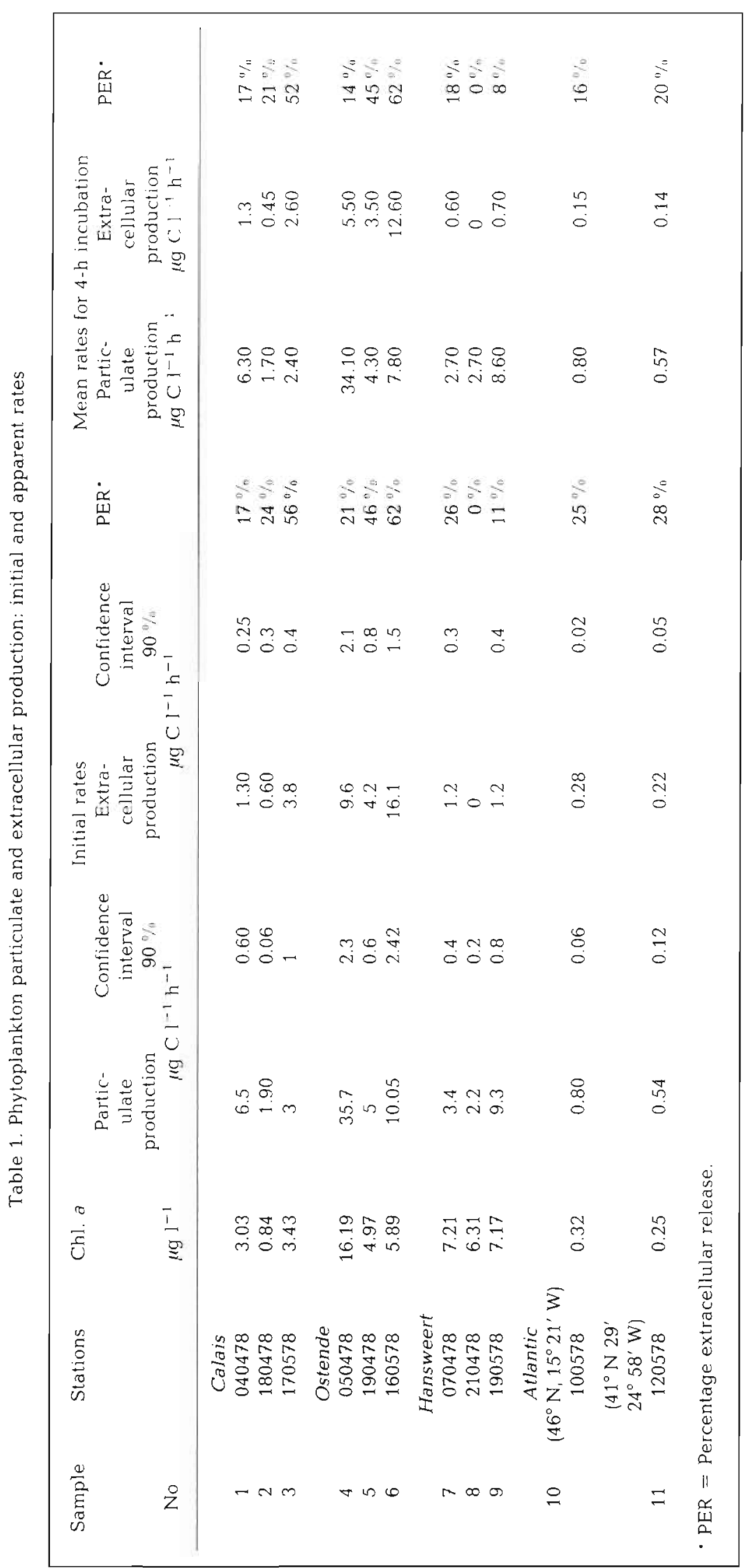


This table shows that the percentage values of phytoplankton extracellular release range between 0 and $62 \%$ with the lower values in the eutrophied Scheldt estuary. This finding is in agreement with the results obtained by Thomas (1971) and Berman and HolmHansen (1974).

On the other hand, the classical geographical trend of a higher phytoplankton extracellular release with more oligotrophic conditions claimed by these authors is not supported by our results: the extracellular release percentage of the poor Atlantic waters is lower than those of the English Channel and the Southern North Sea measured at the same time (Table 1).

However, seasonal variations show that the percentage of marine phytoplankton excretion increases during the course of a bloom (lowering of the productivity index) from about $20 \%$ to $60 \%$, probably because some essential nutrients for the multiplication of phytoplankton cells are depleted. More data are needed for definite conclusions.

\section{DISCUSSION}

\section{Initial and Apparent Phytoplankton Excretion Rates}

Short-term kinetics have shown that phytoplankton excretion rates can be underestimated either due to a lag phase in the phytoplankton extracellular release and/or to heterotrophic uptake during the incubation.

In order to evaluate the error incurred when longterm incubation is used for measuring excretion rates, Tables 1 and 2 give a comparison between the initial

Table 2. Underestimate percentage of particulate and extracellular production rates measured after 4 -h incubation

\begin{tabular}{|ccccc}
\hline Sample No. & $\begin{array}{c}\text { Particulate } \\
\text { production } \\
\%\end{array}$ & $\begin{array}{c}\text { Extracellular } \\
\text { production } \\
\%\end{array}$ \\
\hline 1 & $3 \%$ & (c) & $0 \%$ & $0 \%$ \\
2 & $11 \%$ & (a) & $25 \%$ & $(\mathrm{a})$ \\
3 & $20 \%$ & (c) & $32 \%$ & $(\mathrm{~b})$ \\
4 & $4 \%$ & (c) & $46 \%$ & $(\mathrm{~b})$ \\
5 & $14 \%$ & (c) & $17 \%$ & (c) \\
6 & $22 \%$ & (c) & $22 \%$ & (c) \\
7 & $21 \%$ & (a) & $68 \%$ & (a) \\
8 & $10 \%$ & (c) & $0 \%$ & \\
9 & $8 \%$ & (c) & $42 \%$ & (b) \\
10 & $0 \%$ & & $46 \%$ & (a) (b) \\
11 & $0 \%$ & & $36 \%$ & (a) (b)
\end{tabular}

(a) 'Lag phase' in the extracellular release.

(b) Heterotrophic uptake of the phytoplankton extracellular production.

(c) Phytoplankton respiration and/or mortality. rate and the apparent rate calculated for a 4-h incubation (time commonly used for the measure of primary production in the North Sea).

From Table 2 it appears that the particulate phytoplankton production can be underestimated occasionally by up to $22 \%$. Considering the $90 \%$ confidence level chosen, only 4 samples are significantly underestimated. This underestimate must be attributed either to the presence of a lag phase because of slow metabolism (Samples No. 2 and 7) either to phytoplankton cell respiration or mortality (Samples No. 1 and 5). Underestimates of phytoplankton excretion rates are more important and can reach $68 \%$. As can be seen from Table 2, significant underestimates explained by the presence of a lag phase in the extracellular release kinetics occur especially in oligotrophic environments (Atlantic waters) but also in the Scheldt estuary (Sample No. 7). The high turbidity of this last biotope probably explains the low metabolism of the weakly illuminated phytoplankton cells. Heterotrophic uptake of phytoplankton extracellular products, on the other hand, occurs in all the biotopes sampled (often after a phytoplankton bloom) but not especially in the Scheldt with maximum heterotrophic activity (Billen et al., 1979). Products of exoenzymatic hydrolysis of exogenous or endogenous organic material, not excretion products of phytoplankton, are probably the mean source of heterotrophic activity in this estuarine ecosystem.

Consequently, the shape of the kinetic curve of phytoplankton extracellular products (lag phase, linear, non-linear) is not characteristic of a single biotope (coastal, estuary, open-sea). Under these circumstances, the choice of a uniquely appropriate incubation time is difficult and kinetics will thus give a better approximation of gross phytoplankton excretion rates. Nevertheless, few kinetic times are required, providing they are carefully selected according to the productivity and the heterotrophic uptake expected.

\section{Relative Heterotrophic Uptake of the Phytoplankton Extracellular Products}

Relative heterotrophic uptake can be calculated from the evolution curve of ${ }^{14} \mathrm{C}$ phytoplankton excretion products using a simple mathematical model. Let us consider the model of Figure 8 where the pool of excreted compounds $E$ is supposed to be stationary. Under these conditions, the time evolution of the extracellular ${ }^{14} \mathrm{C}$ products $\left(E^{*}\right)$ is given by the equation:

$$
\frac{d E^{*}}{d t}=\text { e.a. } \mathrm{CO}_{2}-h \frac{E^{*}}{E}
$$

with $e=$ phytoplankton excretion; ${ }^{\mathrm{a}} \mathrm{CO}_{2}=$ specific activity of dissolved carbonate; $h=$ heterotrophic 
uptake of phytoplankton extracellular products $E$; $\frac{E^{*}}{E}=$ specific activity of extracellular organic products in this equation $\frac{h}{E}=\frac{1}{\tau}$

Where $\frac{1}{\tau}=$ relative heterotrophic uptake of extracellular compounds $E$

Equation (1) can be written:

$$
\frac{d E^{*}}{d t}=\text { e.a. } \mathrm{CO}_{2}-\frac{1}{\tau} E^{*}
$$

the analytical solution of which is

$$
E^{*}=\text { e.a. } \mathrm{CO}_{2} \cdot \tau\left(1-\exp \frac{-t}{\tau}\right)
$$

Figure 9 shows the kinetic curves $E^{*}=f(t)$ calculated from Equation (2) for various values of $1 / \tau$. As can be seen from this figure, a minimal relative heterotrophic uptake of 0.05 of the phytoplankton extracellular pro-

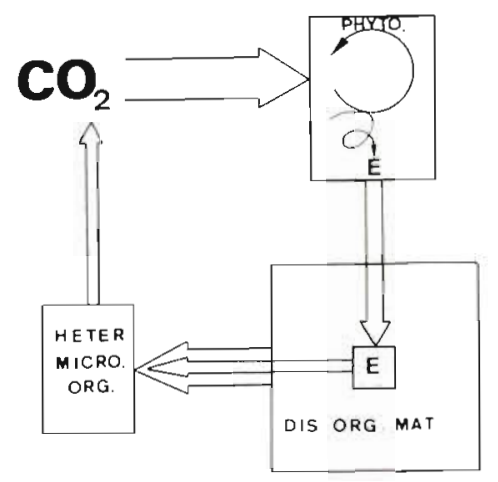

Fig. 8. Schematic representation of the model of heterotrophic utilization of phytoplankton-excreted products. E: see legend to Figure 9

ducts is needed to observe a significant change in the phytoplankton excretion rate (relative error on a single measure is $10 \%$ ) during a 4 -h incubation. This value can be compared with the microbiological uptake rates of small organic molecules measured on the same samples by Billen et al. (1979). Because they are directly assimilable by heterotrophs, small organic molecules alone are considered although macromole-

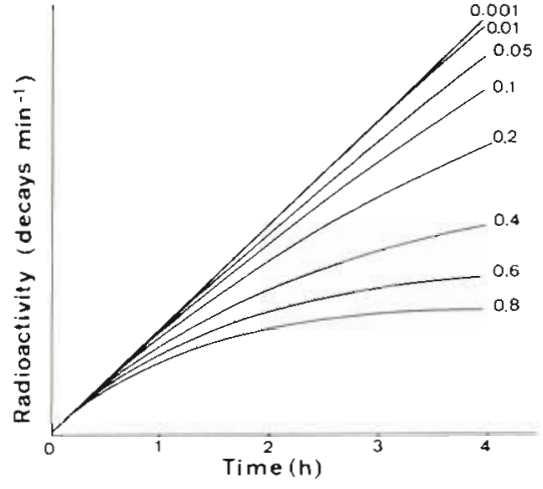

Fig. 9. Kinetic curves of phytoplankton-excreted products $(E=f[t])$ for various values of $1 / \tau$

cules are also to be found in the phytoplankton excretion products (Hellebust, 1974). Among the possible excreted small organic molecules, Billen et al. (1979) have chosen three amino acids (aspartate, alanine and lysine), one carbohydrate monomer (glucose) and three organic acids (glycollate, lactate and acetate). Range values found for the three biotopes investigated are summarized in Table 3 . This table shows that the 0.05 calculated value of $1 / \tau$ is within the range of the measured microbiological uptake rates in the estuarine and coastal area but is too high for the open-sea. Consequently, if Billen et al.'s values are correct, 4-h kinetics should be too short to measure an eventual heterotrophic uptake of phytoplankton extracellular products in open-sea.

Table 3. Extreme values of relative heterotrophic uptake $(1 / \tau)$ of small organic molecules ${ }^{\circ}$

\begin{tabular}{|lcc|}
\hline \multicolumn{1}{c}{ Biotopes } & \multicolumn{2}{c|}{ minimum $^{1 / \tau\left(\mathrm{h}^{-1}\right)}$} \\
\hline Scheldt estuary & 0 & 0.12 \\
Coastal Southern & 0 & 0.12 \\
$\quad$ North Sea & 0 & 0.02 \\
English Channel & & \\
- From Billen et al. (1979). & & \\
\hline
\end{tabular}

\begin{tabular}{|c|c|c|c|c|}
\hline Samples & Stations & Date & $\tau^{-1}\left(\mathrm{~h}^{-1}\right)$ & $\begin{array}{l}\text { Range of values for } \tau^{-1}\left(\mathrm{~h}^{-1}\right) \\
\text { measured by Billen et al. (1979) }\end{array}$ \\
\hline 4 & Ostende & 050478 & 0.39 & $0.001-0.03$ \\
\hline 3 & Calais* & 170578 & 0.16 & 0 \\
\hline 9 & Hansweert & 190578 & 0.27 & $0-0.11$ \\
\hline 10 & $46^{\circ} \mathrm{N}, 15^{\circ} 21^{\prime} \mathrm{W}$ & 100579 & 0.34 & not measured \\
\hline 11 & $41^{\circ} 29^{\prime} \mathrm{N}, 24^{\circ} 58^{\prime} \mathrm{W}$ & 120579 & 0.15 & not measured \\
\hline
\end{tabular}

Table 4. Relative heterotrophic uptake of phytoplankton extracellular products 
As an application of this model, the relative heterotrophic uptake of the phytoplankton excretion products $1 / \tau$ has been calculated from our own experiments. Among all the kinetics performed only five allow the calculation of $1 / \tau$ (Table 4 ). For other cases, the incubation period must be prolonged for observing an eventual uptake.

The $1 / \tau$ values of 0.39 (Sample No. 4), 0.16 (Sample No. 3) and 0.27 (Sample No. 9) seem to be too high when compared with the microbiological utilization of small organic molecules measured on the same samples by Billen et al. (1979).

This discrepancy should be explained either by momentary non-stationariness due to a sudden increase of the phytoplankton extracellular production (Billen et al., 1979) or by an important phytoplankton excretion of special molecules not included in the small organic molecules tested and quickly taken up by the heterotrophic microorganisms.

This last possibility cannot be excluded although the small organic molecules were carefully selected in the three main classes of the possibly excreted compounds (amino acids, sugars and organic acids).

New experiments are thus urgently needed to determine the nature of marine phytoplankton excreted products and their eventual uptake by heterotrophs.

Acknowledgements. This work is a contribution to the Belgian National Environment Project, it was financially supported by the Ministry of Science Policy. I wish especially to thank $M$. Somville, G. Billen and $M$. Loyens for technical help. I am grateful to G. Billen for commenting on the manuscript and to D. Michel for help in the analytical resolution of the model.

\section{LITERATURE CITED}

Anderson, G. C. and Zeutschel, R. P. (1970). Release of dissolved organic matter by marine phytoplankton in coastal and offshore areas of the Northeast Pacific Ocean. Limnol. Oceanogr., 15, 402-407

Berman, T. and Holm-Hansen, O. (1974). Release of photoas- similated carbon as dissolved organic matter by marine phytoplankton. Mar. Biol., 25, 305-310.

Billen, G., Joiris, C., Wynant, J and Gillain, G. (1979) Concentration and microbiological utilization of small organic molecules in the Scheldt estuary, the Belgian coastal zone of the North sea and the English Channel. Submitted to Estuar. \& Coast. Mar. Sci.

Choi, C. I. (1972). Primary production and release of dissolved organic carbon from phytoplankton in the Western North Atlantic Ocean. Deep Sea Res., 19, 731-735

Hellebust, J. A. (1965). Excretion of some organic compounds by marine phytoplankton. Limnol. Oceanogr., 10, 192-206

Hellebust, J. A. (1974). Extracellular products. In W.D.P. Stewart (Ed.), Algal Physiology and Biochemistry, Botanical Monographs, Vol. 10. Blackwell, Oxford pp. 838-863.

Joiris, C. (1977). On the role of heterotrophic bacteria in marine ecosystems: Some problems. Helgoländer wiss. Meeresunters., 30, 611-621.

Kelton, R., McKinley, K. R., Ward, A. K. and Wetzel, R. G. (1977). A method for obtaining more precise measures of excreted organic carbon. Limnol. Oceanogr., 22, 570-573.

Lorenzen, C. (1967). Determination of chlorophyll and phaeopigments: spectrophotometric equations. Limnol. Oceanogr., 12, 343-347.

Nalewajko, C., Dunstall, T G. and Shear, H. (1976). Kinetics of extracellular release in axenic algae and in mixed algal-bacteria [ cultures: significance in estimation of total (gross) phytoplankton excretion rates. J. Phycol., 12, 1-5.

Samuel, S., Shan, N. H. and Fogg, G. E. (1971). Liberation of extracellular products of photosynthesis by tropical phytoplankton. J. mar. biol. Ass. U.K., 51, 793-798.

Smith, W O. Jr. (1974). The extracellular release of glycolic acid by a marine diatom. J. Phycol., 10, 30-33.

Smith, W O. Jr., Barber, R. T. and Huntsman, S. A. (1977) Primary production of the coast of northwest Africa: excretion of dissolved organic matter and its heterotrophic uptake. Deep Sea Res., 24, 35-47

Steeman Nielsen, E. (1952). The use of radioactive carbon $\left({ }^{14} \mathrm{C}\right)$ for measuring organic production in the sea. J. Cons. pernn. int. Explor. Mer, 18, 117-140.

Thomas, J. P. (1971). Release of dissolved organic matter from natural populations of marine phytoplankton. Mar. Biol., 11, 311-323.

Williams, P. J. and Yentsch, C. S. (1976). An examination of photosynthetic production, excretion of photosynthetic products, and heterotrophic utilization of dissolved organic compounds with reference to results from a coastal subtropical sea. Mar. Biol., 35, 31-40. 